\title{
GREENLANDIC WASTE INCINERATION FLY AND BOTTOM ASH AS SECONDARY RESOURCE IN MORTAR
}

\author{
G.M. KIRKELUND, L.M. OTTOSEN, P.E. JENSEN \& P. GOLTERMANN \\ Department of Civil Engineering, Technical University of Denmark, Denmark
}

\begin{abstract}
Today, 900 tons incineration fly ash is shipped abroad annually from Greenland for deposits, whereas the 6,000 tons incineration bottom ash is deposited locally. These incineration ashes could be valuable in concrete production, where the cement has to be shipped to Greenland. For this purpose, the effects on compressive strengths of mortars by substituting cement or sand by raw, washed and electrodialytically treated fly ash or bottom ash were investigated.

Parts of the experimental fly ash had been pre-treated by either washing with distilled water or electrodialytically treated to remove salts and by the latter method, also heavy metals. Mortar samples were cast where cement $(5 \%-20 \%)$ or sand $(5 \%-10 \%)$ was replaced with fly ash or bottom ash, together with references without replacements. The compressive strengths were measured after 7, 14, 28 and 42 days. Replacing cement by fly ash resulted in lower compressive strength at $20 \%$ content of fly ash. At $5 \%$ replacement with raw fly ash a compressive strength similar to the reference was seen. However, using washed and electrodialytically treated ash lead to lower strengths. The lowest compressive strength was seen when replacing both sand with bottom ash and cement with fly ash.

Based on the compressive strength tests, it is found that using Greenlandic incineration ashes in mortar as $5 \%$ cement replacement could consume all ash instead of disposals, and could thus turn the ashes into a local resource and simultaneously reduce the import of cement.

Keywords: arctic, bottom ash, colour, compressive strength, concrete, electrokinetic, fly ash, mortar, setting time, washing.
\end{abstract}

\section{INTRODUCTION}

Concrete is a widely used construction material due to the high compressive strength, formability, good insulation and fire resistant properties. Concrete consists of mortar and aggregates; and mortar consists of binder, typically cement, water and sand. Pigment can be added to mortar to colour the concrete or chemicals to increase/delay the setting times. The production of cement is responsible for approximately $5 \%$ of the total $\mathrm{CO}_{2}-$ emissions, so there is focus on producing 'green mortar' or 'green concrete'. Substituting primary resources with secondary resources such as incineration residues in mortar is of growing interest and has shown potential for APC residues after removing the leachable heavy metals [1] and sewage sludge ash [2, 3].

Greenland implemented six small municipal solid waste incineration (MSWI) plants in the 1990s to substitute uncontrolled disposal sites. The resulting mineral residues from MSWI are fly ash and bottom ash. The fly ash is collected by electrostatic precipitators (ESP). This equipment is capable of removing particulate material only, thus gaseous contaminants such as volatilized metals and acids escape and are emitted to the atmosphere. Alkaline fly ash contains high concentrations of leachable heavy metals and salts, which classifies fly ash as 
hazardous waste. Today, 900 tons of fly ash is shipped annually for deposits in Norway (disposal in Greenland is prohibited), which implies considerate economical spending for the Greenlandic municipalities. The 6,000 tons of bottom ash is still deposited at the local and uncontrolled disposal sites. The bottom ash could be valuable in constructions and have shown some potential as a secondary resource in road construction [4]. The concrete production in Greenland use app. 20,000 tons of cement annually and the whole production of cement is imported to Greenland from Denmark. Use of local resources in the construction sector would benefit both the environment and the local economy.

The aim of this study was to investigate if Greenlandic fly ash and bottom ash had potential as secondary resources in mortar, by comparing and substituting cement and sand by ash.

\section{MATERIALS AND METHODS}

\subsection{Experimental incineration residues}

Incineration residues from the waste incinerator in Sisimiut, Greenland were used in this study. Fly ash (FA) was collected from big bags, where the fly ash is stored temporarily prior to end disposal. Bottom ash (BA) was collected directly from the plant, before disposal at the disposal site.

\subsubsection{Pretreatment of fly ash}

A part of the fly ash sample was washed (WFA) as pre-treatment, to remove the soluble salts, by the following procedure. Fly ash and distilled water were mixed to an L/S (liquid-to-solid ratio) 5 and shaken vigorously for 1 minute. After settling, the water was decanted. This procedure was repeated three times, to ensure all salts had been removed. Before using the washed fly ash in the mortar, it was dried at $105^{\circ} \mathrm{C}$.

Another part of the fly ash sample was subjected to electrodialytic remediation (EDFA) [5] to remove both soluble salts and also easily removable heavy metals. This remediation method uses a direct current to remove ionic species from a suspension of contaminated material, in this case the fly ash. The fly ash has been treated for 5 hours and a significant reduction in heavy metal leaching had been obtained [6].

\subsubsection{Pretreatment of bottom ash}

Larger objects (stones, metal pieces, ceramics etc.) were removed manually from the bottom ash, before sieving the bottom ash and using only the fraction below $4 \mathrm{~mm}$ for replacement of sand.

\subsection{Analytical methods}

Total heavy metal concentrations $(\mathrm{Cd}, \mathrm{Cr}, \mathrm{Cu}, \mathrm{Pb}, \mathrm{Zn})$ in the ashes were measured by ICPOES (induced coupled plasma - optical emission spectrometry) after pre-treatment by DS259 [7] where $1 \mathrm{~g}$ of fly ash and $20 \mathrm{ml} 7.3 \mathrm{M} \mathrm{HNO}_{3}$ were heated at $200 \mathrm{kPa}\left(120^{\circ} \mathrm{C}\right)$ for $30 \mathrm{~min}$. The liquid was subsequently separated by vacuum filtration through a $45 \mu \mathrm{m}$ filter and diluted to $100 \mathrm{ml}$. The units used in this paper are $\mathrm{mg} / \mathrm{kg}$ for concentrations in dry matter. Water content was measured after heating at $105^{\circ} \mathrm{C}$ for 24 hours. Loss on ignition was measured after heating at $550^{\circ} \mathrm{C}$ for 1 hour. The $\mathrm{pH}$ was measured in $1 \mathrm{M} \mathrm{KCl}$ at a liquid-to-solid ratio (L/S) of 5 and after 1 hour of agitation, $\mathrm{pH}$ was measured by a Radiometer Analytical $\mathrm{pH}$ 
electrode. The amount of water soluble fly ash was estimated as mass reduction when mixing $1 \mathrm{~g}$ fly ash with $20 \mathrm{ml}$ distilled water, agitated for 24 hours.

Particle size distribution was measured by laser diffractometry for the fly ash samples and the cement, whereas for the bottom ash and sand, sieves with masks between $63 \mu \mathrm{m}$ and $8 \mathrm{~mm}$ were used.

Scanning electron microscope (SEM) for main morphology was performed on fly ash and cement. For the SEM analysis, a small sub-sample of the material $(<0.5 \mathrm{~g})$ was placed directly on carbon tape. No further pre-treatment of the samples was made. The accelerating voltage of the SEM was $30 \mathrm{keV}$ with large field detector (and X-ray cone).

\subsection{Mortar samples}

For the preparation of mortar, Basis Cement from Aalborg Portland and 0/4 mm quartz sand of class E from RN Sten \& Grus, Hvidovre, Denmark were used. The mortar was mixed according to EN 196-1 [8] at a water/binder-ratio of 0.5 and a sand/cement ratio of 3 (reference mix $225 \mathrm{ml}$ water, $450 \mathrm{~g}$ cement and 1,350 $\mathrm{g}$ sand). To some of the mortars small additional amounts of water was added to achieve similar workability as the reference mortar, which slightly changed the w/b-ratio. The cement, sand or both were substituted by different weight percentage of fly ash or bottom ash, see compositions in Table 1, 12 experimental mortars were made. Three to six $4 \mathrm{~cm} \times 4 \mathrm{~cm} \times 16 \mathrm{~cm}$ rectangular prism mortar bars were cast for each mix in wooden moulds and demoulded after 1 day, if possible. The mortar samples with $10 \%$ and $20 \%$ ash replacement were only possible to demould after, 2 and 6 days, respectively. The mortars were cured horizontally in water baths.

Compressive strength was tested in both ends of each rectangular prism mortar bar. From this procedure, a six to twelve double determination of the compressive strength for each mortar mix was obtained.

The setting time was tested by use of the Vicat needle according to DS/EN 196-3 [9], with the slight modification that the test was made on mortar samples instead of cement. The setting time was measured on eight different mortars with replacement with raw and washed fly ash.

Table 1: Mortar mixtures, speciation of substitutions, FA-raw fly ash, WFA-washed fly ash, EDFA, electrodialytically treated fly ash, BA-bottom ash.

\begin{tabular}{|c|c|c|c|c|c|}
\hline Sample & Curing (days) & Raw fly ash & Washed fly ash & ED fly ash & Bottom ash \\
\hline Reference & $7,14,28,42$ & & & & \\
\hline $5 \% \mathrm{FA}$ & $7,14,28,42$ & $\mathrm{X}$ & & & \\
\hline $5 \%$ WFA & 14 & & $\mathrm{X}$ & & \\
\hline $5 \%$ EDFA & $7,28,42$ & & & $\mathrm{X}$ & \\
\hline $5 \% \mathrm{FA}+5 \% \mathrm{BA}$ & 7 & $\mathrm{X}$ (cement) & & & $\mathrm{X}$ (sand) \\
\hline $5 \% \mathrm{EDFA}+5 \% \mathrm{BA}$ & 7 & & & $\mathrm{X}$ (cement) & $X$ (sand) \\
\hline $10 \% \mathrm{FA}$ & $7,14,28,42$ & $\mathrm{X}$ & & & \\
\hline $10 \%$ FA-sand & 14 & $\mathrm{X}$ & & & \\
\hline $10 \%$ WFA-sand & 14 & & $\mathrm{X}$ & & \\
\hline $10 \%$ WFA & 14 & & $\mathrm{X}$ & & \\
\hline $20 \%$ FA & 14 & $\mathrm{X}$ & & & \\
\hline $20 \%$ WFA & 14 & & $\mathrm{X}$ & & \\
\hline
\end{tabular}


Table 2: Ash characteristics.

\begin{tabular}{lllll}
\hline Parameter & Fly ash & Washed fly ash & ED treated fly ash & Bottom ash \\
\hline $\mathrm{LOI}(\%)$ & $5.9 \pm 0.1$ & - & - & 0.8 \\
$\mathrm{pH}$ & $11.2 \pm 0.01$ & - & - & 13.3 \\
Water content $(\%)$ & $0.7 \pm 0.1$ & - & 4.9 & 0.3 \\
Water solubility $(\%)$ & $53 \pm 1$ & - & 20 & 1.8 \\
$\mathrm{Cl}(\mathrm{mg} / \mathrm{kg})$ & 320,000 & 9,300 & 3,000 & 50 \\
$\mathrm{SO}_{4}(\mathrm{mg} / \mathrm{kg})$ & 24,000 & 1,200 & 4,700 & 700 \\
$\mathrm{Cd}(\mathrm{mg} / \mathrm{kg})$ & 129 & 305 & 474 & 6 \\
$\mathrm{Cr}(\mathrm{mg} / \mathrm{kg})$ & 103 & 204 & 195 & 72 \\
$\mathrm{Cu}(\mathrm{mg} / \mathrm{kg})$ & 1,554 & 3,414 & 2,075 & 1,219 \\
$\mathrm{~Pb}(\mathrm{mg} / \mathrm{kg})$ & 6,350 & 16,300 & 8,060 & 1,036 \\
$\mathrm{Zn}(\mathrm{mg} / \mathrm{kg})$ & 28,600 & 77,000 & 53,045 & 40,400 \\
\hline
\end{tabular}

\section{RESULTS}

\subsection{Ash characteristics}

Table 2 shows the chemical characteristics of the ash samples. The ashes were rich in heavy metals and pre-treatment of the fly ash increased the heavy metal concentrations. Heavy metals could be removed by the washing process and was removed by the electrodialytic treatment [6], but due to dissolution of soluble phases in the fly ash, seen as 53\% water solubility, the concentrations in the ash increased. The content of $\mathrm{Cu}, \mathrm{Pb}$ and $\mathrm{Zn}$ in the bottom ash is linked to the presence of metal pieces. For reuse purposes and use as supplementary cement material, the $\mathrm{Cl}$ should not be too high $(<1 \%)$, mainly as it would corrode steel in reinforcements, but could also affect the setting time and compressive strength [10]. High sulfate content could result in unwanted expansions of concrete and is regulated to be less than $3 \%$ if coal fly ash is used in concrete [11]. Leaching of heavy metals from fly ash can be a drawback of using such materials, however, incorporation of air pollution control residues into mortars has shown no significant difference in heavy metal leaching [1,12]; however, the long-term leaching of mortar with incineration residue replacement has not yet been studied.

As the fly ash and bottom ash are intended for the replacement of cement and sand in mortar, the similarity in particle size and morphology are compared. Figure 1 shows the particle size distributions and Fig. 2 shows SEM picture of the fly ashes compared to cement.

The particle sizes of the EDFA ash increased slightly compared to the raw fly ash and a similar tendency will be expected for the washed ash. Both fly ash samples have larger particle sizes than the cement, which they will replace. This could have an influence on the compressive strength of the mortars.

Comparing the particle size distribution of the bottom ash to the sand, it is seen that the bottom ash was not as evenly distributed as the sand, and the bottom ash consisted of largersized pieces.

The fly ash particles were irregular-shaped particles with large surface areas, which differed in size and mainly distributed as agglomerates. Pretreating the fly ash by washing and electrodialytic treatment removed most of the soluble salts, making the particles look slightly 


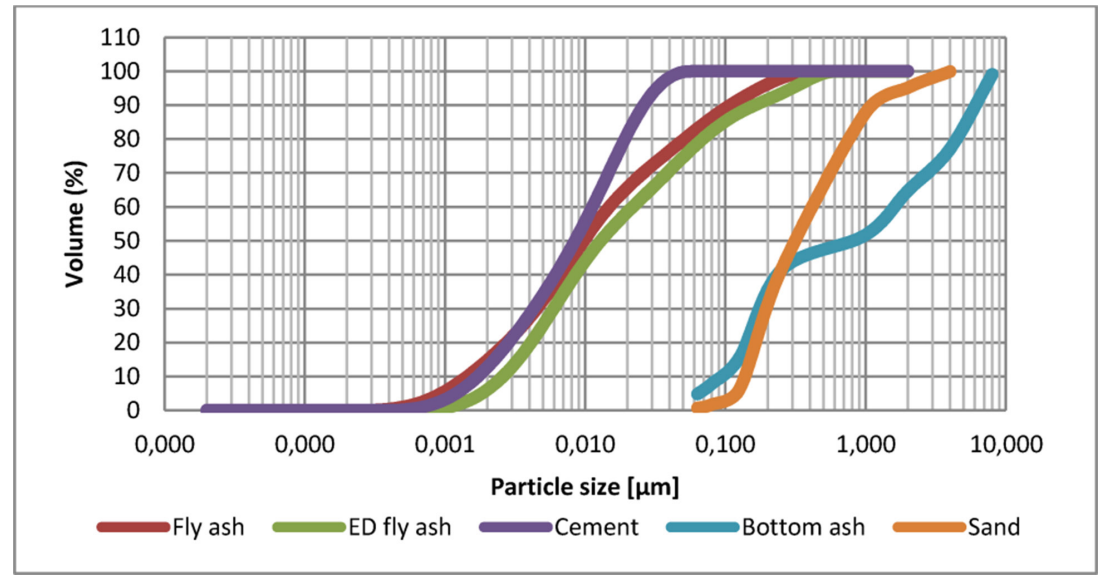

Figure 1: Particle size distribution of the used materials.

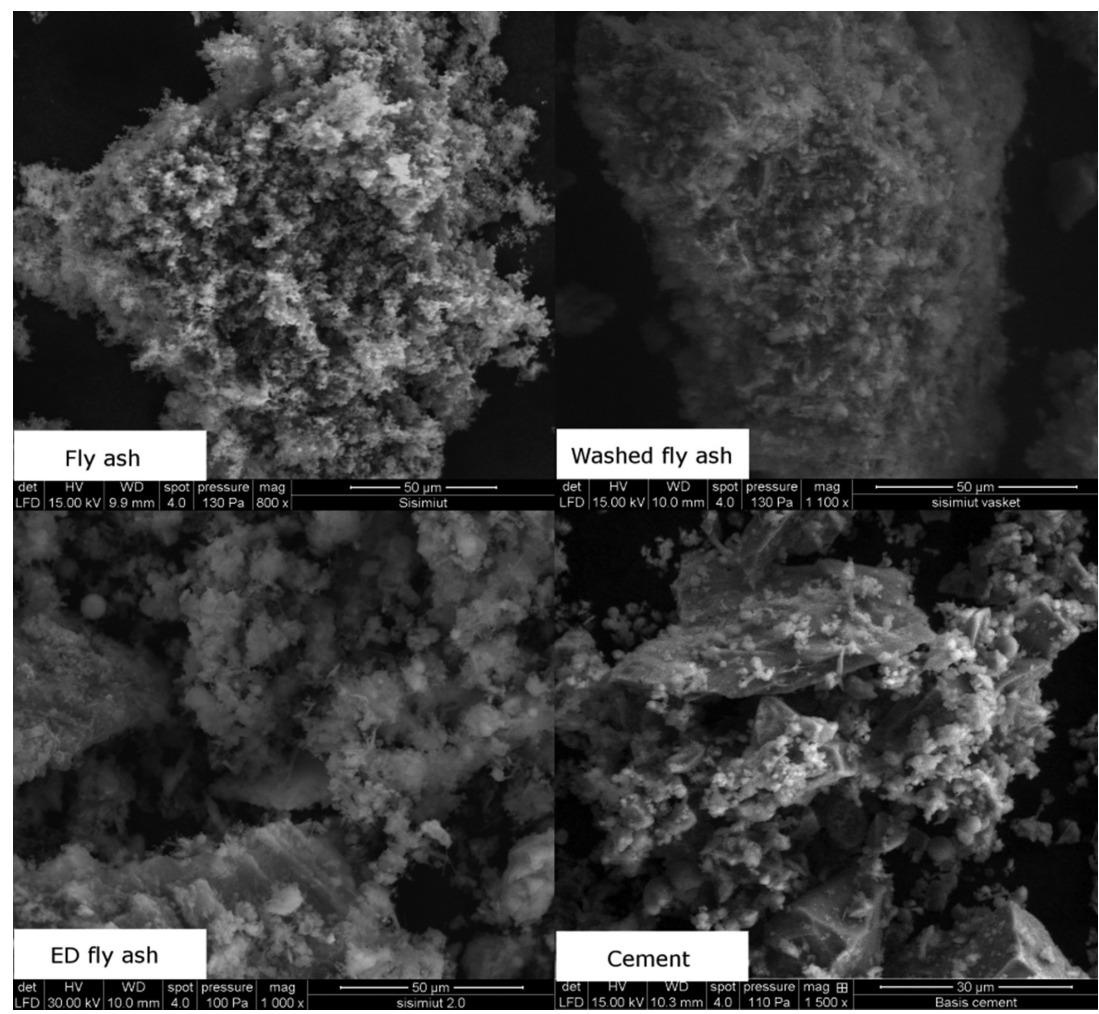

Figure 2: SEM pictures of fly ash samples and cement. 
less porous. These salts can be seen in the raw fly ash as crystals on the particle surface in Fig. 2, and were less prominent in the pretreated fly ashes. The general shape of the fly ash particles did not change with pretreatment. The cement particles were angular, generally smaller and appeared less porous than the fly ash particles. The particle size of the cement and fly ash can influence the hydration rate. Smaller particle sizes increases the hydration rates and accelerates strength development, especially within the first 7 days [10].

\subsection{Compressive strength}

Figure 3 shows the normalised compressive strength with increasing cement replacement by either raw or washed fly ash, after 14 days of curing. The normalisation is based on the compressive strength (MPa) of the actual sample compared to the reference sample's compressive strength (MPa). Therefore the compressive strength for the reference sample is given as 1 . For 5 and 10\% replacement, the compresseive strength was close to the compresseive strength for the reference sample with no clear difference between the raw or washed ash. Replacing $20 \%$ of cement by fly ash showed a significantly lower compressive strength and the samples were also more difficult to mix and demould, which is also reflected by the larger standard deviations for these samples.

The normalised strength development over time for up to $10 \%$ cement replacement with fly ash is shown in Fig. 4. It is seen that the electrodialytic treated fly ash (EDFA) developed the strength at a later stage (after 28 days) than the raw fly ash. The EDFA samples were also more difficult to mix and demould, which can be seen in the larger standard deviations for these samples. After 42 days of curing, the samples with fly ash have similar compressive strength and also similar or slightly higher than the reference sample. Generally, the compressive strength was higher in the samples with 5\% cement replacement than $10 \%$ cement replacement by raw fly ash, indicating an optimal replacement quantity.

Normalised compressive strength of mortar samples where sand was replaced by fly ash or bottom ash is shown in Fig. 5. For two of the samples, cement was additionally substituted by fly ash (5\% FA $+5 \% \mathrm{BA}$ and 5\% EDFA $+5 \% \mathrm{BA})$. Replacing sand by fly or bottom ash reduced the compressive strength compared to the reference and more than by replacing

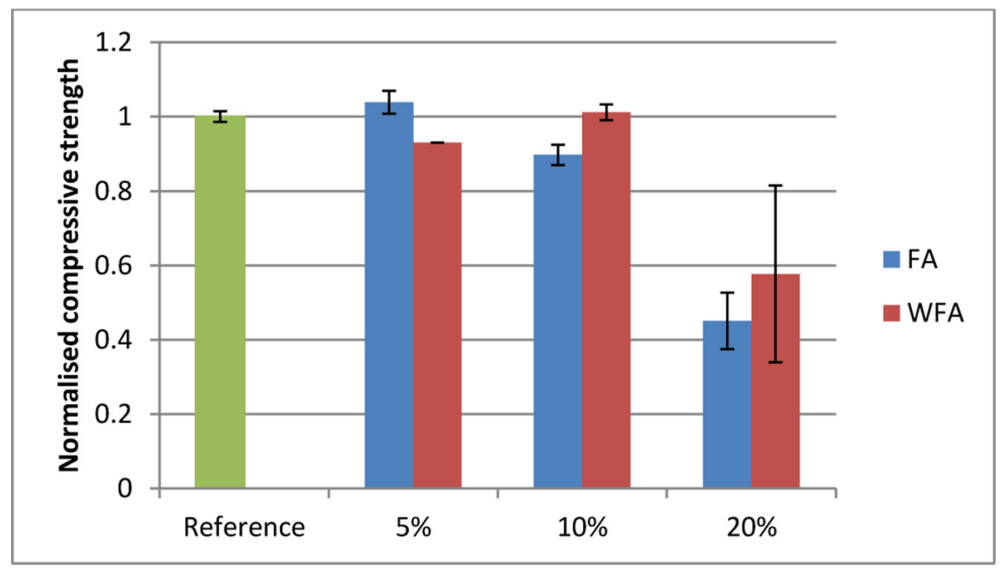

Figure 3: Compressive strength with standard deviation for 14 days mortar samples with increasing ash content. FA-raw fly ash, WFA-washed fly ash. 


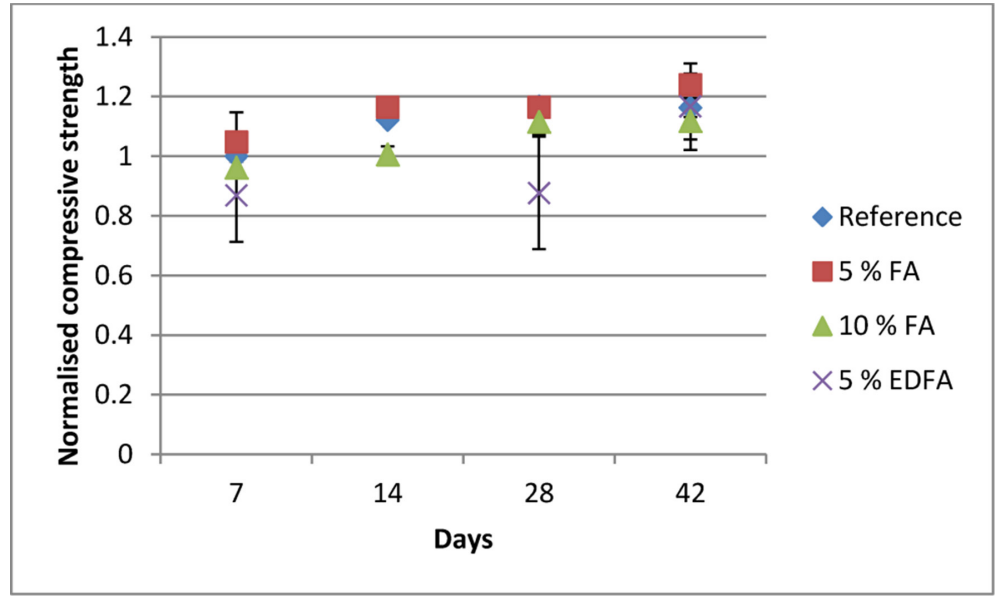

Figure 4: Strength development over time with replacement of raw fly ash (FA) and electrodialytically treated fly ash (EDFA) with standard deviations. No sample for 14 days for the $5 \%$ EDFA.

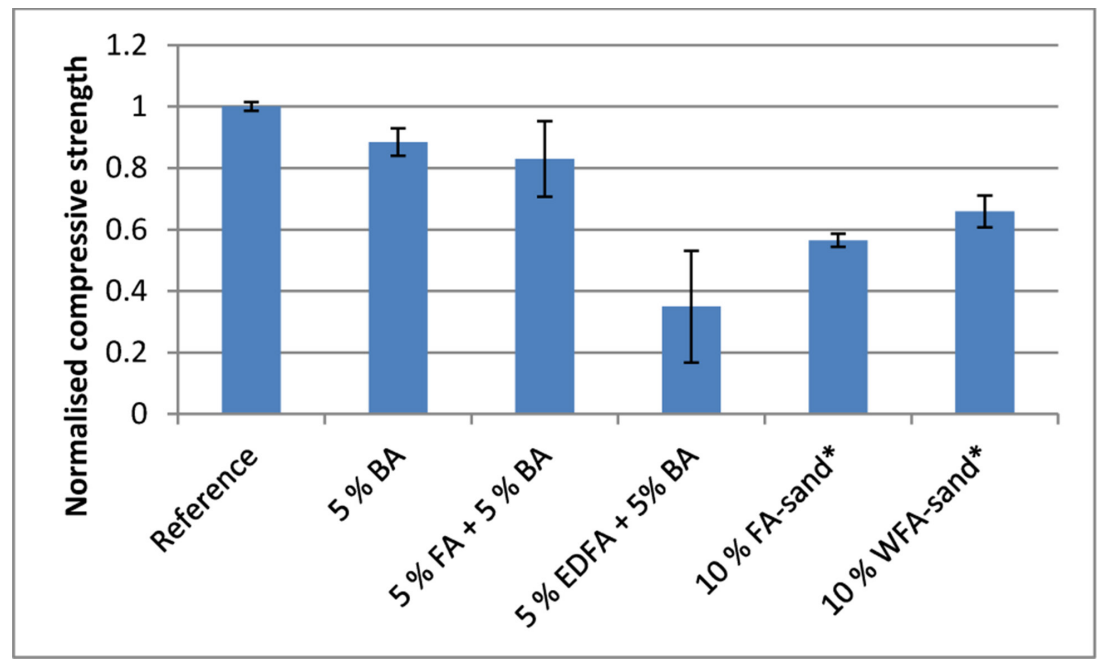

Figure 5: Compressive strength with standard deviation for samples with sand replacement for 7 days and 14 days* curing. BA-bottom ash, FA-raw fly ash, EDFAelectrodialytical treated fly ash, WFA-washed fly ash.

cement by fly ash (Fig. 4). Generally, better results were achieved when sand was replaced by bottom ash instead of fly ash, which are also more similar in particle size. The lowest compressive strength was seen for the 5\% EDFA + 5\% BA sample.

\subsection{Setting times}

Table 3 shows the setting times for the mortar mixtures. It is seen that the setting time is retarded by the replacement of fly ash. Increasing the replacement percentages of fly ash 
further increased the setting times. At 5\% replacement, the washed fly ash results in longer setting time than the untreated fly ash. At $10 \%$ and $20 \%$ replacement, this difference between the raw and washed fly ash is less prominent. The setting times was not investigated for mortars with the electrodialytic treated fly ash, but is expected to be in the same range as for mortar with washed fly ash. The pretreatment seems to remove soluble phases that are possible hydration phases in the fly ash. Setting time retardation of concrete samples with $25 \%$ replacement of cement by coal fly ash (often referred to as fly ash in concrete literature) is seen to be less than 1 hour compared to reference concrete [10]. Delays in initial setting times has been found to be up to a factor 6 for mortars with electrodialytically treated APC (air pollution control) residues [1] and a factor 7-17 for raw APC residues [13] from waste incineration compared to a reference mortar. The delay in setting times depend on several factors such as the amount of cement, water requirement and the reactivity and type of fly ash [10] as well as soluble compounds in the fly ash. The very long setting time for the mortar samples with $20 \%$ replacement of cement and $10 \%$ replacement of sand also resulted in some segregation of the paste and aggregates in the samples, which leads to a weak mortar, as was seen in the compressive strength tests. Thus, such amounts of replacement in mortar would not be desirable.

However, Chen et al. 2013 [14] showed that setting times can be significantly decreased if the fly ash is milled prior to replacement, due to higher activation energy achieved with the smaller particle size. The smaller particle size would also increase the compressive strength and the milling should be studied further for the MSWI fly ash. For more optimal replacement, the samples could be altered in particle size by milling. Mechanical milling for 30 seconds of sewage sludge ash prior to mortar casting has shown increase the compressive strength compared to mortar with raw sewage sludge ash [2]. Wet milling for 96 hours of water extracted MSWI fly ash showed similar compressive strength to the reference mortar, when replacing 5\% and $10 \%$ of the cement with ash [14]. The main effect by the milling is strengthened filler effect and pozzolanic reactions by the smaller particle sizes and larger surface area [14]. Retardation of set and compressive strength is dependent on many factors, and the ashes are a chemical complex material compared to the cement and sand which it has been replacing in this study. Salts and heavy metals can influence the mortar properties and it is not fully understood and should be investigated in future studies.

Table 3: Setting times for mortar samples.

\begin{tabular}{lc}
\hline Mortar sample & Setting time (Vicat) (h:min) \\
\hline Reference & $4: 00$ \\
$5 \%$ FA & $19: 30$ \\
$5 \%$ WFA & $23: 30$ \\
$10 \%$ FA & $29: 30$ \\
$10 \%$ WFA & $26: 30$ \\
$20 \%$ FA & $70: 00$ \\
$20 \%$ WFA & $70: 30$ \\
$10 \%$ FA-sand & $70: 00$ \\
\hline
\end{tabular}




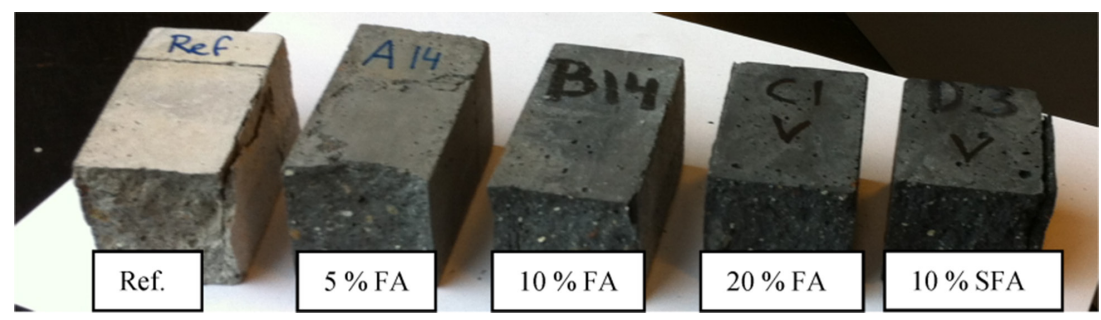

Figure 6: Colours of mortar with fly ash.

\subsection{Colouring of mortar by fly ash}

The MSWI fly ash was black and washing it intensified the black colour. When replacing cement with fly ash, the mortars became increasingly darker grey with increasing amount of fly ash, as seen in Fig. 6.

The black microsilica, which is also used as supplementary material in mortar, has also been seen to give concrete a darker grey colour [10]. Kappel et al. [15] suggested that sewage sludge ash could be used to colour concrete and that different milling time of the ash and use of different surfaces in the mortars results in different colours and accentuations, which could be architectural interesting. Normally, MSWI fly ash is grey with a colour similar to cement. The incineration plant in Sisimiut incinerates used motor oil, as a support fuel if the waste is very wet, which could colour the fly ash. The colour of the fly ash from Sisimiut could vary over the seasons and samples should be taken to evaluate this potential.

\section{CONCLUSION}

Greenlandic incineration residues could have potential as a secondary resource in mortar, to replace either cement, sand or both. Replacing 5\% and 10\% of both raw and pre-treated fly ash by cement in mortar, resulted in only slightly lower compressive strengths compared to reference mortar. However, the workability is reduced and the setting times delayed with increasing replacement amount of fly ash. Pre-treatment in the form of washing and electrodialytic treatment even reduced the workability further. The fly ash has similarities to cement and bottom ash to sand, especially in the particle size distribution. Milling and reducing the particle size could improve both the compressive strength and setting time for mortars with replacement. The fly ash has the most potential as secondary resource in mortar and could also be used to colour mortar. Replacing cement by alternative materials would additionally reduce the import of cement to Greenland and benefit the $\mathrm{CO}_{2}$ reduction further.

\section{ACKNOWLEDGEMENTS}

Civil engineering students Randi Juel Olsen, Marlene Mia Westmose Hansen and Villads Seiling Reichel are thanked for the mortar casting and testing and laboratory technicians Sabrina June Hviid, Marlene Grønvold and Ebba Schnell for the chemical analysis.

\section{REFERENCES}

[1] Kirkelund, G.M., Geiker, M.R. \& Jensen, P.E., Electrodialytically treated MSWI APC residue as substitute for cement in mortar. Nordic Concrete Research, 49(1), pp. 1-16, 2014. 
[2] Ottosen, L.M., Jensen, P.E., Goltermann, P. \& Kirkelund, G.M., Sewage sludge ash as cement replacement after simple pretreatment. Proceedings Sardinia 2013, Fourteenth International Waste Management and Landfill Symposium.

[3] Goltermann, P., Ottosen, L., Jensen, P.E. \& Kirkelund, G.M., ZeroWaste: turning waste into a new, sustainable resource for concrete. Proceedings of the XXII Nordic Concrete Research Symposium, Reykjavik, Iceland, pp. 233-236, 2014, ISBN 978-82-8208-043-9.

[4] Kirkelund, G.M., Jensen, P.E. \& Ottosen, L.M., Electrodialytic extraction of heavy metals from Greenlandic MSWI fly ash as a function of remediation time and L/S ratio. Proceedings of the 10th International Symposium on Cold Regions Development, pp. 87-96, 2013.

http://dx.doi.org/10.1061/9780784412978.009

[5] Jensen, P.E., Ferreira, C.M.D., Hansen, H.K., Rype, J.U., Ottosen, L.M. \& Villumsen, A., Electroremediation of air pollution control residues in a continuous reactor. Journal of Applied Electrochemistry, 40(6), pp. 1173-1181, 2010. http://dx.doi.org/10.1007/s10800-010-0090-1

[6] Kirkelund, G.M. \& Jensen, P.E., Electrodialytic treatment of municipal solid waste incineration fly ash - removal of heavy metals and evaluation of matrix changes for reuse. In Preparation.

[7] DS 259, Determination of metals in water, sludge and sediments - General guidelines for determination by atomic absorption spectrophotometry in flame, 2003.

[8] DS/EN 196-1, Methods of testing cement - Part 1: Determination of strength, 2005.

[9] DS/EN 196-3, Methods of testing cement - Part 3: Determination of setting times and soundness, 2009.

[10] Kosmatka, S.H., Kerkhoff, B. \& Panarese, W.C. (eds), Design and Control of Concrete Mixtures, EB001 14th edn., Portland Cement Association: Skokie, Illinois, USA, 2002.

[11] DS/EN 450-1, Fly ash for concrete - Part 1: Definition, specifications and conformity criteria, 2007.

[12] Lima, A.T., Ottosen, L.M. \& Ribeiro, A.B., Assessing fly ash treatment: remediation and stabilization of heavy metals. Journal of Environmental Management, 95, pp. S110-S115, 2012.

[13] Geiker, M.R., Kjeldsen, A.M., Galluci, E. \& Bager, D.H., Preliminary investigation of the effect of air-pollution-control residue from waste incineration on the properties of cement paste and mortar. Proceedings for Advances in Cement and Concrete X, Davos, Switzerland, 2006.

[14] Chen, C.G., Sun, C.J., Gau, S.H., Wu, C.W. \& Chen, Y.L., The effects of the mechanical-chemical stabilization process for municipal solid waste incineration fly ash on the chemical reactions in cement paste. Waste Management, 33, pp. 858-865, 2013.

http://dx.doi.org/10.1016/j.wasman.2012.12.014

[15] Kappel, A., Ottosen, L.M., Kirkelund, G.M., Bache, A. \& Goltermann, P., The colour potentials of SSA-containing mortar. Proceedings for Concrete - Innovation and Design, fib Symposium, Copenhagen, Denmark, pp. 18-20, 2015. 